\title{
Proposta de limites para monitoramento da qualidade do concreto
}

\author{
Antônio S. G. Falcão, M.Eng. \\ Programa de Pós-Graduação em Eng ${ }^{a}$ de Produção - UFRGS \\ Porto Alegre/RS \\ falcaoas@terra.com.br \\ Flávio S. Fogliatto, Ph.D. \\ Programa de Pós-Graduação em Eng ${ }^{a}$ de Produção - UFRGS \\ Porto Alegre/RS \\ ffogliatto@ppgep.ufrgs.br
}

Neste artigo propõe-se a utilização do CEP para o monitoramento da qualidade do concreto utilizado na construção civil e discute-se sobre o atual parâmetro utilizado para avaliar a qualidade daquele insumo. Dentre as várias características que determinam a qualidade do concreto foca-se na sua resistência à compressão que, usualmente, é visualizada por produtores e consumidores como uma característica do tipo maior-é-melhor. Neste artigo discute-se sobre essa caracterização da resistência à compressão do concreto e propõe-se um limite de especificação superior para aquele parâmetro de qualidade. Em um caso exemplo, mostra-se os ganhos financeiros resultantes da utilização desse limite de especificação superior.

Palavras-chave: controle da qualidade do concreto; CEP aplicado à construção civil; construção enxuta.

In this paper we propose an SPC-based strategy for monitoring the quality of concrete used in civil construction and discuss about the parameter actually used for the evaluation of the quality of that material. Among the several characteristics that determine the quality of concrete we focus on the compression resistance, which is usually viewed as a larger-is-better type of characteristic by concrete producers and consumers. We propose an upper speclimit for that characteristic and show, in a case example, the financial gains resulting from using such limit.

Keywords: concrete quality control; SPC applied to civil construction; lean construction.

\section{Introdução}

No atual ambiente competitivo, a eficiência produtiva e a qualidade apresentam-se como fatores de sobrevivência no meio empresarial. Atender às expectativas dos consumidores e manter sua confiança são fatores motivadores da busca de melhorias e, com o atual direcionamento em relação à competição entre empresas, evidenciam-se como de fundamental importância. Diante desse quadro, tanto empresas como consumidores estão cada vez mais preocupados com a qualidade dos produtos fabricados ou serviços prestados. Nesse aspecto, diversas ferramentas para o controle de qualidade foram propostas nas últimas décadas, com o objetivo de assegurar a fabricação de produtos e/ou prestação de serviços livres de defeitos. Dentre essas ferramentas pode-se destacar o Controle Estatístico do Processo (CEP).

O CEP pode ser definido como um sistema de inspeção por amostragem que tem como objetivo indicar a presença de causas especiais, potencialmente prejudiciais à qualidade dos produtos manufaturados (RIBEIRO e TEN CATEN, 2000). A ocorrência de causas especiais pode ser identificada através da utilização de cartas de controle (CCs). Essas cartas são gráficos que apresentam a evolução temporal do comportamento de uma característica de interesse. CCs utilizam como dados de entrada medições de características que influenciam na qualidade dos itens produzidos. Medições são realizadas em pontos espaçados no tempo e registradas nas cartas; este registro resulta em gráficos apresentando os valores de medição da característica no eixo vertical e os pontos no tempo nos quais as medições são efetuadas no eixo horizontal. A cada medição, compara-se o resultado obtido com limites de controle; a ocorrência de medições fora destes limites ou de padrões não-aleatórios na distribuição dos pontos indica a presença de causas especiais de variabilidade. Uma vez identificadas as causas especiais, pode-se atuar sobre elas, melhorando continuamente a qualidade do produto. CCs permitem a redução sistemática da variabilidade nas características de 
qualidade do produto, melhorando, assim, a qualidade intrínseca do que está sendo produzido.

Neste artigo propõe-se a utilização do CEP no controle da qualidade do concreto utilizado para a construção de edificações habitacionais. A aplicação do CEP no monitoramento da qualidade do concreto foi motivada por constatações empíricas acerca de problemas de qualidade em peças concretadas, tais como presença de fissuras em lajes e elementos estruturais com resistência à compressão abaixo da especificação de projeto. A proposta de implementação do CEP deu-se através de estudo prático em uma empresa construtora de edifícios residenciais; nesta empresa foram coletados dados utilizados como subsídio para o desenvolvimento do estudo.

Através do uso de cartas de controle, principal elemento do CEP, monitora-se, neste estudo, o principal parâmetro de qualidade do concreto: a sua resistência à compressão. O objetivo é avaliar a capacidade do fornecedor dessa matéria-prima de atendimento às exigências do consumidor (empresa analisada), bem como ao que preceituam as normas técnicas de fornecimento e controle de concreto vigentes no país.

Este artigo apresenta uma importante contribuição na área de controle da qualidade de materiais utilizados na construção civil. Através da aplicação do CEP, demonstra-se que consumidores de concreto podem estar sujeitos a perdas ao adquirirem o produto. Tais perdas estão vinculadas ao parâmetro atualmente utilizado para aferição da qualidade de uma estrutura de concreto armado, o $f_{c k}$ (resistência à compressão característica do concreto). De acordo com considerações de norma (ABNT, 1978), pode-se aceitar uma estrutura de concreto armado, desde que mantidas suas características geométricas, baseando-se no atendimento do valor mínimo de resistência especificada em projeto. Contudo, essa é uma visão estritamente técnica, que favorece o produtor e pode prejudicar o consumidor por não considerar parâmetros máximos para a aceitação do produto. Pelo parâmetro atual, são considerados próprios para uso concretos que apresentem resistência maior ou igual à especificação de projeto. Ou seja, não existem restrições quanto à produção de concreto com elevados valores de resistência. Todavia, conforme se apresenta neste artigo, existem perdas associadas à não consideração de um limite superior para a aceitação do concreto. Elevados valores de resistência à compressão significam elevado consumo de materiais, especificamente o cimento. Levando-se em consideração que para o consumidor o que interessa é o valor de resistência à compressão especificado em projeto, valores acima do mínimo representam custos adicionais, à medida que pressupõem maior consumo de materiais. Ressalta-se, também, que a produção de concreto com elevados valores de resistência podem interferir na qualidade final da estrutura.

Neste artigo, propõe-se considerar, além do limite inferior atualmente utilizado $\left(f_{c k}\right)$, o estabelecimento de um limite superior de especificação para a aceitação do concreto, de forma a evitar ou reduzir perdas impostas aos consumidores. Nesse sentido, o artigo apresenta o CEP como uma ferramenta de melhoria eficaz e de simples aplicação para o controle do recebimento de concreto em obra, podendo ser amplamente utilizada por empresas do setor.

O restante deste artigo está assim organizado: inicialmente, apresenta-se conceitos básicos referentes ao controle da qualidade do concreto, que servem de subsídio para o estudo. Na seqüência, são apresentados os fundamentos estatísticos do CEP, utilizados na pesquisa. Em seguida, apresenta-se a nova proposta para o monitoramento da qualidade do concreto através da análise de dados coletados em campo e se discute os resultados obtidos. Por fim, são feitos comentários finais e apresenta-se as conclusões do estudo realizado.

\section{Fundamentação Teórica}

\section{Controle da qualidade do concreto}

A resistência à compressão é utilizada como parâmetro principal de dosagem do concreto, sendo adotada por ocasião do dimensionamento da estrutura. Portanto, está diretamente relacionada à segurança estrutural. Uma obra deve ser construída com um concreto de resistência igual ou superior àquele valor adotado no projeto (HELENE e TERZIAN, 1992). A importância da resistência à compressão é reconhecida no texto da NBR 6118 (ABNT, 1978), quando prevê a aceitação automática da estrutura, desde que tenham sido mantidas as características geométricas dos elementos estruturais (por exemplo, prumo dos pilares, nivelamento de vigas e lajes, seções transversais etc.), com base no atendimento ou não dessa propriedade do concreto conforme especificado em projeto.

Experimentalmente, sabe-se que a Distribuição Normal é um modelo matemático que pode representar de maneira satisfatória a distribuição da resistência de um certo volume de concreto, que pode ser descrita completamente por seus parâmetros de média e desvio-padrão (NEVILLE, 1997). Para simplificar a descrição da distribuição de resistência e eliminar o inconveniente de trabalhar com dois valores distintos, reduz-se os dois parâmetros da Distribuição Normal a um único valor característico de resistência, denominado resistência à compressão característica do concreto, designado por $f_{c k}$ (NEVILLE, 1997; HELENE, 
1980). $O f_{c k}$ corresponde ao $5^{\circ}$ percentil da distribuição do valor de resistência à compressão, sendo utilizado tanto como especificação na elaboração do projeto estrutural, como parâmetro de dosagem na produção do concreto. Os estimadores dos parâmetros da Distribuição Normal de $f_{c k}$ são dados por: elevado não porque as operações de ensaio tenham elevado o seu valor real, mas sim porque essa é a maior resistência à compressão que o concreto ensaiado pode apresentar à idade de ensaio. Essas condições são consideradas por norma (ABNT, 1996) que estabelece que cada exemplar é constituído por

$$
f_{c m}=\frac{\sum_{i=1}^{n} f_{c i}}{n}
$$$$
S_{c}=\sqrt{\frac{\sum_{i=1}^{n}\left(f_{c m}-f_{c i}\right)^{2}}{n-1}}
$$

onde $f_{c m}$ é a resistência média do concreto obtida a $j$ dias de idade, em MPa; $f_{c i}$ é a resistência à compressão individual de cada um dos $n$ exemplares de uma amostra, a $j$ dias de idade, em MPa; e $S_{c}$ é o desvio-padrão do processo de produção e ensaio do concreto obtido de uma ou mais amostras, a $j$ dias de idade, em MPa.

No Brasil, a resistência à compressão do concreto é obtida através da tensão de ruptura à compressão axial de um corpo-de-prova (CP) cilíndrico, sendo que, para edificações, as dimensões desse CP podem ser $100 \times 200$ $\mathrm{mm}$ ou $150 \times 300 \mathrm{~mm}$ de diâmetro e altura, respectivamente. Para obter-se o valor da resistência à compressão, o $\mathrm{CP}$ deve ser mantido em cura úmida até a idade de ensaio, devendo ser rompido saturado. $\mathrm{O}$ resultado representa a resistência à compressão potencial do concreto que está sendo produzido ou entregue em obra e, normalmente, é expresso em megapascais (MPa).

Essas recomendações e procedimentos procuram oferecer as melhores condições para que o concreto dos CPs desenvolva sua máxima resistência potencial (HELENE, 1980). O valor da resistência potencial do concreto obtido na operação de ensaio corresponde ao valor de referência para o dimensionamento da estrutura e, conseqüentemente, para a fixação de sua segurança. Esse valor deve ser único e perfeitamente definido a fim de possibilitar a correta comunicação entre etapas de projeto e execução de uma obra (NEVILLE, 1997).

Desde que seja admitido que os CPs referentes a um mesmo exemplar são curados juntos, nas mesmas condições, não há possibilidade de se obter um resultado mais elevado do que o fornecido por um ensaio correto (HELENE, 1980). Portanto, ao se analisar os resultados de dois CPs de uma mesma produção que deve possuir uma só resistência, deve-se desprezar aquele $\mathrm{CP}$ que apresentar menor resistência à compressão, pois certamente uma das operações de ensaio foi a causadora dessa diminuição.

O valor mais alto é menos afetado negativamente pelas operações de ensaio e representa mais apropriadamente a resistência potencial do concreto, que é o que se procura obter. Ou seja, esse valor é mais dois CPs da mesma produção e moldado no mesmo ato e deve-se tomar, como resistência desse exemplar, o maior dos dois valores obtidos no ensaio.

\section{Fundamentos estatísticos do CEP}

Cartas de controle, independentemente do tipo, baseiam-se nos mesmos princípios fundamentais de construção e operação. As CCs apresentam uma linha central que representa a média da variável de interesse quando o processo está sob controle (ou livre de causas especiais) e duas outras linhas que representam os limites de controle do processo. Limites de controle são definidos de forma a compreender a maior parte dos valores da variável, estando o processo sob controle. Na sequiência, apresenta-se o desenvolvimento matemático das CCs para variáveis com tamanho de amostra unitário.

Considere medições individuais $x_{1}, x_{2}, \ldots, x_{\mathrm{i}}$ de uma variável de interesse. A determinação da linha central e dos limites de controle seguem um modelo geral, onde $x_{i}$ é a estatística amostral que representa a variável de interesse, com média $\mu_{0}$ e desvio-padrão $\sigma$ conhecidos. Assim, o limite de controle superior (LCS), a linha central (LC) e o limite de controle inferior (LCI) são dados por (MONTGOMERY, 1996):

$\mathrm{LCS}=\mu_{0}+\mathrm{L} \sigma, \quad \mathrm{LC}=\mu_{0}, \quad \mathrm{LCI}=\mu_{0}-\mathrm{L} \sigma$,

onde $L$ é a distância, em desvios-padrão, entre os limites de controle e a linha central. O valor de $L$ mais comumente utilizado em CCs é $L=3$, o que pode ser justificado pelos bons resultados obtidos na prática.

Em grande parte das aplicações de CCs para valores individuais, os parâmetros $\mu_{0}$ e $\sigma$ são desconhecidos, sendo estimados a partir de amostras obtidas da variável de interesse. Considere disponíveis $n$ medições individuais da variável de interesse. Os estimadores amostrais de $\mu_{0}$ e $\sigma$, designados por $\hat{\mu}_{0}$ e ô são:

$$
\hat{\mu}_{0}=1 / n \sum_{i=1}^{n} x_{i} \quad \text { e } \quad \hat{\sigma}=\bar{R} / d_{2}
$$


onde $\bar{R}$ é a média das amplitudes móveis de defasagem 1 calculadas a partir da amostra (existem $n$ - 1 amplitudes) e $d_{2}$ é uma constante tabelada (ver MONTGOMERY, 1996).

Os parâmetros na eq. (2) permitem o monitoramento do nível da variável de interesse; o monitoramento de sua dispersão demanda uma segunda CC, para amplitudes móveis, com os seguintes parâmetros (DUNCAN, 1986):

$$
\mathrm{LCS}=D_{4} \bar{R} ; \quad \mathrm{LC}=\bar{R} ; \quad \mathrm{LCI}=D_{3} \bar{R}
$$

onde $D_{3}$ e $D_{4}$ são constantes tabeladas em Duncan (1986), entre outros. As amplitudes móveis utilizadas no esquema de monitoramento na eq. (4) são correlacionadas, o que resulta na incidência de ciclos constantes na CC, comprometendo sua eficiência na detecção de desvios na variabilidade média do processo. Por este motivo, a maioria dos esquemas de monitoramento para variáveis com tamanho de amostra unitários utiliza somente as CCs com parâmetros dados na eq. (2).

A utilização das CCs para valores individuais pressupõe variáveis de interesse normalmente distribuídas (BOTHE, 1997). Tal suposição também se aplica nos estudos de capacidade para estas variáveis. A capacidade de um processo, monitorado por uma variável de interesse, pode ser definida como a sua habilidade de atender a especificações pré-estabelecidas. Em estudos de capacidade, confronta-se a variabilidade natural apresentada pelo processo com a amplitude de suas especificações através de índices numéricos. O índice $C_{p k}$ é de particular interesse neste trabalho, sendo dado por(KOTZe LOVELACE, 1998):

$C_{p k}=\min \left|\frac{L E S-\hat{\mu}_{0}}{3 \hat{\sigma}}, \frac{\hat{\mu}_{0}-L E I}{3 \hat{\sigma}}\right|$

onde $L E S$ e $L E I$ são os limites superiores e inferiores de especificação para a variável de interesse. Quanto maior o valor de $C_{p k}$, menor será o número de produtos fora dos limites de especificação (JURAN e GRYNA, 1993). Por essa razão, algumas indústrias utilizam como parâmetro desejado de qualidade um índice $C_{p k}>1,33$, o que implica em uma produção de defeituosos de apenas $0,00633 \%$. Contudo, de forma geral, o índice $C_{p k}$ $\geq 1,0$ é condição necessária para que a fração de defeituosos seja pequena (menor ou igual a $0,27 \%$ ). A análise da capacidade de um processo é um procedimento que evolui a partir do estudo da sua estabilidade. Somente após a eliminação das causas especiais, é possível avaliar se um processo é capaz de atender às especificações de uma determinada variável.

O estudo da capacidade de processos, delineado acima, analisa a conformidade quanto às especificações. Contudo, para direcionar esforços para uma análise mais global, com interpretação econômica das especificações, é recomendado avaliar os processos através da função de perda de Taguchi.

Para medição do nível de qualidade de produtos e processos, o conceito de percentagem não-conforme é amplamente utilizado (TAGUCHI et al., 1990). Todavia, geralmente, a porcentagem de produtos não-conformes é pequena em processos de produção e fabricantes não costumam expedir produtos defeituosos, selecionando, para tanto, itens conformes. Sob essa abordagem, quando produtos não-conformes deixam de ser expedidos, os seus consumidores não são diretamente afetados, a não ser pelo aumento de custo e, conseqüentemente, do preço dos produtos. Assim, existe um custo associado à má qualidade; tal custo refere-se à perda que é imposta ao consumidor pela má qualidade de produtos fabricados, que pode ser expressa em termos monetários, através da função de perda quadrática de Taguchi (JURAN e GRYNA, 1993):

$$
P=k\left(\mu_{0}-\tau\right)^{2}
$$

onde $P$ é a perda monetária, associada ao desvio da meta para a variável em estudo, $\mu_{0}$ é o valor médio da variável, $\tau$ é o valor-alvo e $k$ é o coeficiente de perda de Taguchi, que converte o desvio do alvo em termos monetários. Para determinar o valor de $k$, deve-se conhecer a perda associada a uma determinada realização da variável de interesse. Por exemplo (TAGUCHI et al., 1990):

$$
k=A_{0} / \Delta^{2}
$$

onde $A_{0}$ é o custo de reparo ou substituição do produto e $\Delta$ corresponde ao desvio da meta da variável em estudo, que exigiria reparo ou substituição.

\section{Proposta para o monitoramento da qualidade do concreto}

A sistemática proposta para o monitoramento da qualidade do concreto é apresentada utilizando dados de um estudo de caso. No controle da qualidade do concreto, a resistência à compressão é o principal parâmetro de interesse, sendo o melhor indicador de qualquer alteração que tenha ocorrido no processo de produção desse insumo. Assim, a resistência à compressão é utilizada como variável de controle de qualidade do concreto para aplicação do CEP neste estudo.

Os dados utilizados foram obtidos dos resultados de certificados de ensaios de resistência à compressão axial do concreto, fornecidos por empresa especializada. Nesses certificados constam os resultados de testes de compressão axial realizados em corpos-de- 
prova (CPs), de dimensões $100(\phi) \times 200(\mathrm{~h}) \mathrm{mm}$, para as idades de 3, 7 e 28 dias. No total, foram moldados 1.143 CPs, sendo 748 deles (374 exemplares) para ensaios de compressão aos 28 dias, 255 para os 7 dias e 140 para os 3 dias. Neste estudo, foi monitorada a resistência obtida aos 28 dias, uma vez que o valor da resistência a essa idade corresponde ao valor especificado em projeto; por conseguinte, é o valor mais indicado para controle entre os três apontados.

Dado que as operações de ensaio dos exemplares para obtenção da resistência à compressão do concreto aos 28 dias disponibilizam somente um valor de resistência potencial (valor representativo de cada exemplar ensaiado), dispõe-se de uma amostra de tamanho $n=1$, para análise através das CCs. Nessas condições, cartas para valores individuais são o tipo de CCs indicadas para o monitoramento do processo.

O cálculo dos limites de controle e dos índices de capacidade é realizado supondo que as variáveis em estudo seguem uma distribuição Normal. Caso os dados não sigam esse tipo de distribuição, uma alternativa é utilizar uma transformação nos dados. Pela análise do histograma e dos resultados dos testes de normalidade no quadro da Figura 1, confirma-se, para os dados amostrados, que a produção de concreto segue uma distribuição Normal. Portanto, a análise da estabilidade e a avaliação da capacidade do processo podem ser efetuadas sem a necessidade de transformar os dados.

O estudo da estabilidade do processo de fornecimento de concreto foi desenvolvido utilizando-se cartas de controle para valores individuais e para amplitudes móveis, as quais podem ser visualizadas nas Figuras 2 e 3. As cartas foram geradas com auxílio do software ProCEP (1999). Analisando as CCs, observa-se que o processo apresenta pontos fora dos limites de controle e alguns padrões anormais de comportamento (tais pontos são circundados nas cartas). Conclui-se que o processo analisado é instável no período considerado, com a presença de várias causas especiais (marcadas com linha de contorno). Logo, esse processo não está sob controle estatístico.

Estabilidade é condição necessária para a avaliação da capacidade de um processo. Um processo estável é aquele que está sujeito a somente causas comuns de variabilidade. Desta forma, deve-se proceder a uma investigação das causas da instabilidade, propor e implementar soluções para eliminar os efeitos de tais fatores no processo analisado, tornando-o, então, estável para posterior análise de sua capacidade.

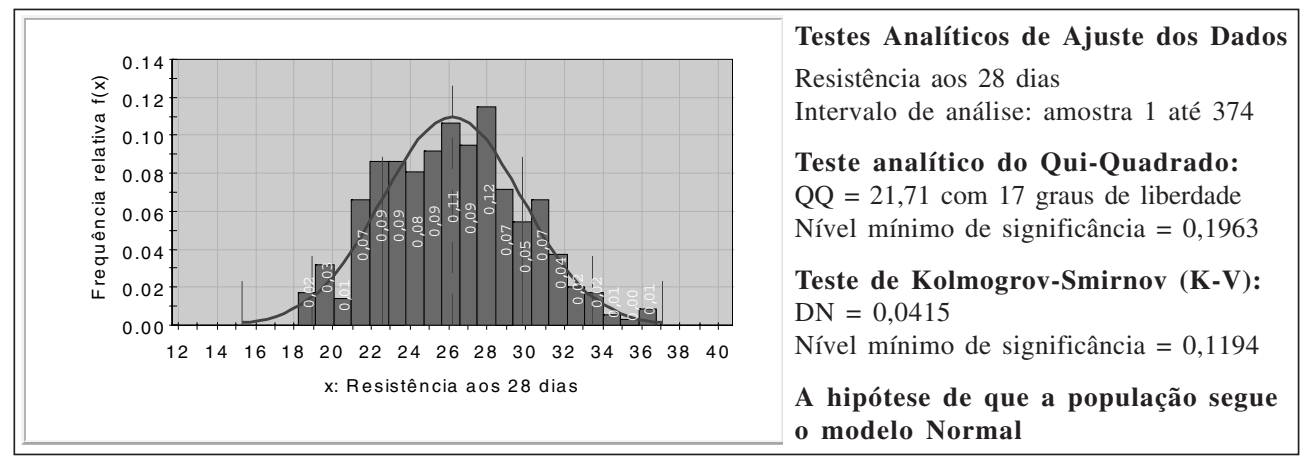

Figura 1 - Quadro com histograma e testes de normalidade dos dados analisados

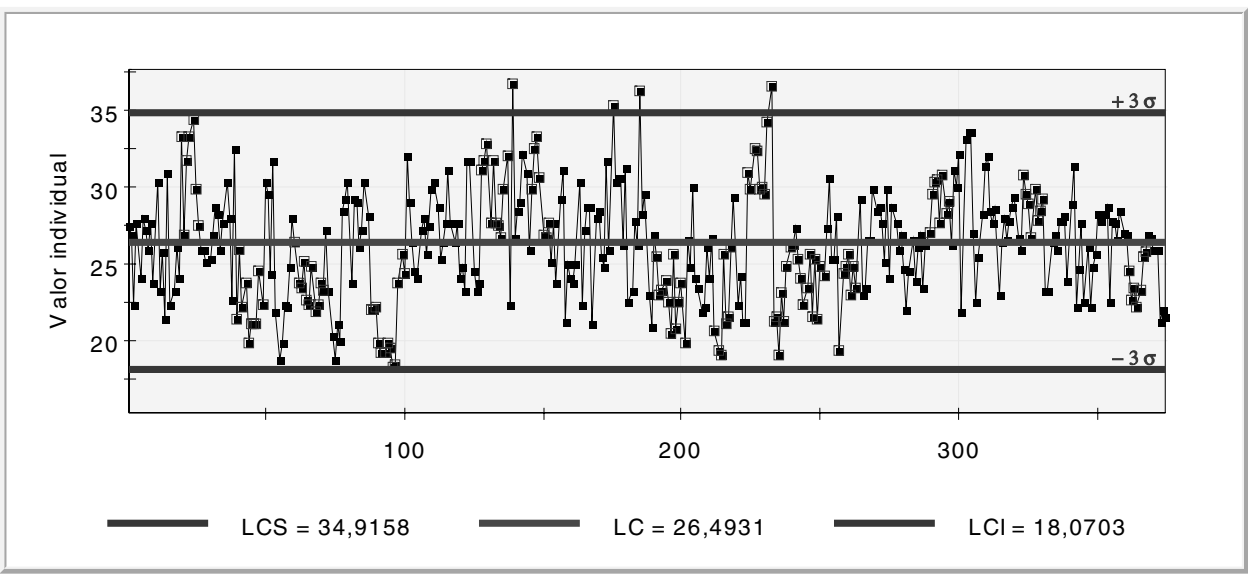

Figura 2 - Carta para valores individuais, período de 22/9/99 a 27/4/00 


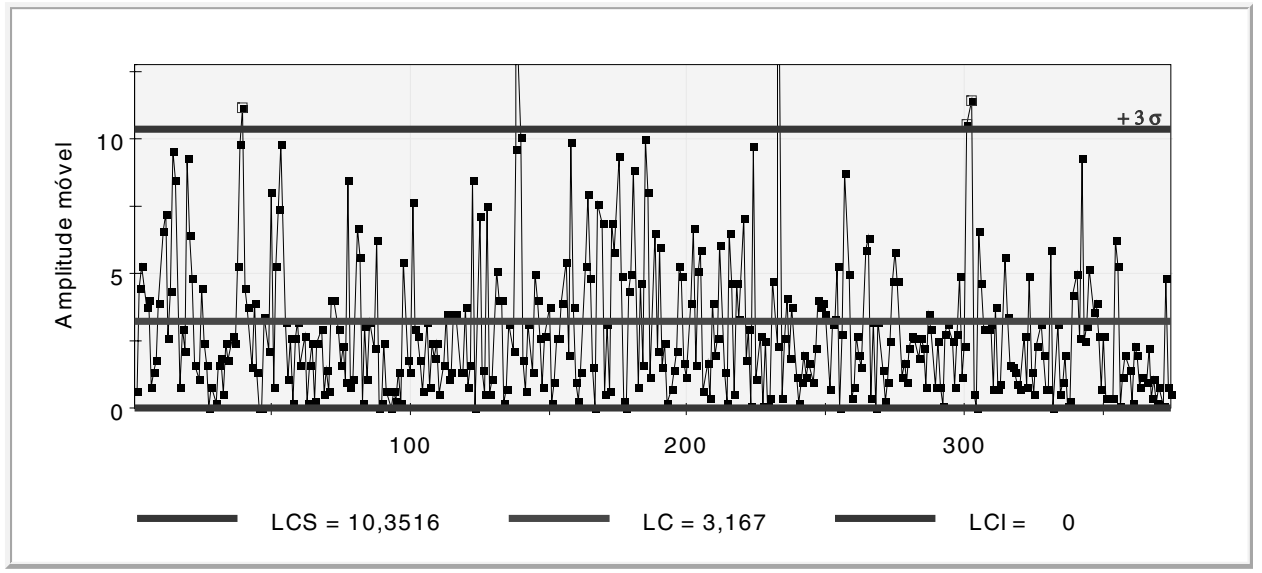

Figura 3 - Carta para amplitudes móveis, período de 22/9/99 a 27/4/00

Existem diversos fatores que intervêm na resistência à compressão do concreto. Pode-se elencar desde a heterogeneidade dos materiais (agregados, cimento, água, aditivos) até o seu transporte, lançamento, adensamento e cura (HELENE, 1980). Como o controle da qualidade da resistência do concreto neste trabalho refere-se à resistência potencial do concreto, medida na saída da betoneira (ver esquema apresentado na Figura 4), os fatores que influenciam na qualidade (resistência) do concreto devem-se aos materiais, à mistura e ao procedimento de ensaio. Os dois primeiros itens mencionados (materiais e mistura) são fatores diretamente relacionados com a produção do concreto, ao passo que o último está relacionado com as operações de ensaio. resistência à compressão que o concreto ensaiado pode obter em uma época específica. Tal procedimento é previsto em Norma (NBR 12655; ABNT, 1996), de tal forma que não seja levado em consideração o efeito dos ensaios à compressão nos resultados obtidos. Logo, a instabilidade apresentada pelo processo analisado provavelmente deve-se exclusivamente ao processo de fabricação do concreto.

Uma análise aprofundada dos fatores que levam o processo sob análise a apresentar-se instável no período estudado foge do escopo deste artigo, que visa tão somente o controle da qualidade do concreto recebido em obra e não de sua fabricação. Dessa forma, fatores que interferem no processo produtivo e

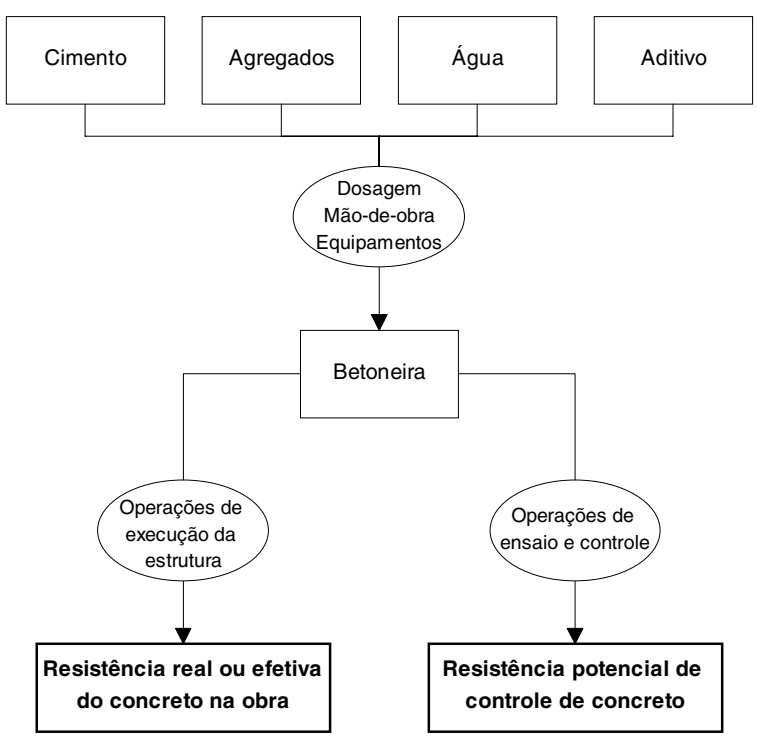

Figura 4 - Obtenção da resistência potencial a partir das operações de ensaio e controle do concreto (Fonte: Helene, 1980, p. 53)

Quanto às operações de ensaio dos $\mathrm{CP}$, descarta-se a influência de seus resultados como fonte de variação na resistência do concreto, ao utilizar-se como resistência potencial o maior valor obtido no ensaio de um exemplar (2 CPs). O maior valor é menos afetado pelas operações de ensaio, correspondendo a maior que são responsáveis pela qualidade do concreto não são aqui discutidos. A seguir, procede-se ao estudo da capacidade do processo analisado.

O estudo de capacidade do processo de fornecimento de concreto refere-se à avaliação da capacidade do 
produtor desse insumo de atender às exigências de seus consumidores e ao estabelecido por Norma (ABNT, 1996; ABNT, 1978). Aqui, a avaliação da capacidade do processo é subdividida em: $i$ ) capacidade técnica e $i$ ) capacidade de limites de produção. O item ( iii) apresenta uma análise de perdas utilizando a função proposta por Taguchi, complementar aos estudos de capacidade.

\section{i. Capacidade Técnica}

O critério da NBR 6118 (ABNT, 1978) recomenda que se aceite o concreto sempre que tenham sido satisfeitas as condições de projeto e execução da Norma, e somente quando a inequação abaixo for satisfeita:

$$
f_{c k j, e s t} \geq f_{c k j}
$$

onde $f_{c k j, e s t}$ é a resistência característica estimada do concreto à compressão aos $j$ dias, $f_{c k j}$ é a resistência característica do concreto à compressão aos $j$ dias, e $j=28$ dias, correspondendo à idade de referência para o dimensionamento de uma estrutura.

Dessa forma, na avaliação da capacidade técnica, o processo é dito capaz se atender à resistência estipulada em projeto, sendo este o valor mínimo a ser atendido pelo produtor do concreto. A finalidade da análise da capacidade técnica é julgar a capacidade do produtor de fornecer concreto que, aos 28 dias, apresente resistência igual ou superior ao valor de projeto. Sendo a resistência do concreto uma característica de qualidade do tipo maior-é-melhor (se o valor mínimo da resistência especificado em projeto for superado, tanto melhor), o processo é dito capaz se pelo menos $99,73 \%$ dos valores de resistência obtidos através de ensaios forem iguais ou maiores que o mínimo exigido em projeto.
Para o caso em estudo, a resistência à compressão mínima exigida pelo consumidor é de $18 \mathrm{MPa}\left(f_{c k}=18\right.$ $\mathrm{MPa}$ ), aos 28 dias. Logo, $f_{c k 28, e s t} \geq 18 \mathrm{MPa}$, ou seja, o limite de especificação inferior do processo é 18 MPa. O não atendimento dessa especificação implicará em perdas ao consumidor.

O quadro da Figura 5 apresenta o estudo da capacidade técnica do fornecimento do concreto, realizado utilizando o software ProCEP (1999). Para a análise da capacidade, foram retiradas as causas especiais que interferem no processo. Portanto, os resultados no quadro da Figura 2 representam um processo submetido a melhorias com vistas à estabilidade.

Observa-se, pela análise dos resultados no quadro da Figura 5, que no período considerado o processo de fornecimento de concreto é capaz de atender às exigências do consumidor. Verifica-se que o valor do $C_{p k}$ é superior a 1, condição que indica que a produção de concreto abaixo do limite de especificação é inferior a $0,27 \%$. Conclui-se, desta forma, que o processo sem causas especiais é capaz de atender seu consumidor e está de acordo com o estabelecido em Norma.

\section{ii. Capacidade dos Limites de Produção}

A avaliação da capacidade dos limites de produção refere-se à análise da capacidade do produtor de fabricar concreto dentro de certas especificações, mínima e máxima, em condições normais de produção, de acordo com o permitido por Norma (ABNT, 1996; ABNT, 1978) e que atenda às exigências do consumidor.

É estabelecido por Norma (ABNT, 1996) que, na dosagem, o traço de concreto a ser produzido seja formulado para alcançar uma resistência média $f_{c j}$ (resistência de dosagem) que assegure, com margem

\section{CAPACIDADE DO PROCESSO}

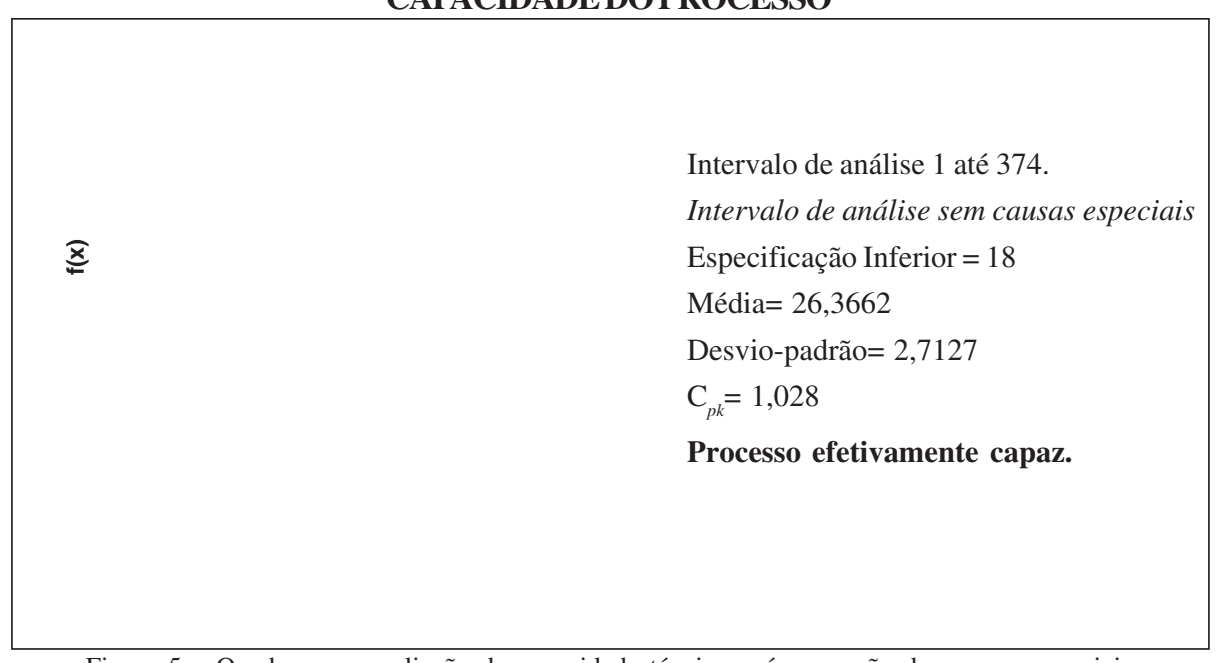

Figura 5 - Quadro com avaliação da capacidade técnica após remoção das causas especiais 
de segurança, que se obtenha na produção a resistência característica à compressão $\left(f_{c k}\right)$ especificada em projeto. Esse é um valor estabelecido de tal forma que garanta que pelo menos $95 \%$ da produção de concreto possua valor igual ou superior ao valor de $f_{c k}$. Por definição, a resistência de dosagem é calculada conforme equação (9) e Figura 6 (ABNT, 1996):

$$
f_{c j}=f_{c k}+1,65 \cdot S_{d},
$$

onde $f_{c j}$ é a resistência de dosagem (resistência média do concreto à compressão prevista para a idade de $j$ dias, em MPa), $f_{c k}$ é a resistência característica do concreto à compressão, em MPa, $S_{d}$ é o desvio-padrão da dosagem, em MPa, e $j=28$ dias (no caso em estudo).

Desta maneira, para que a produção de concreto atenda às especificações de projeto, a dosagem da mistura será efetuada considerando-se que deve existir uma distância entre a resistência característica, $f_{c k}$, estabelecida pelo calculista da estrutura, e a resistência de dosagem, $f_{c j}$, que passa a ser o alvo da produção. A distância mencionada é medida em função do desvio-padrão do processo de produção $\left(S_{d}\right)$, conforme equação (9).

O processo de fabricação do concreto deve, então, ser ajustado para uma produção com média $f_{c j}$ (alvo). Para atender ao que se exige em projeto e não ser rejeitado por não possuir capacidade técnica, o processo deve fabricar com limite inferior dado por $f_{c k}$. Como a Distri- buição Normal é simétrica, o processo também apresenta um limite superior, dado por (ver Figura 4):

$$
L E S=f_{c j}+1,65 \cdot S_{d}
$$

Caso o processo opere sob condições normais de produção e atenda às prescrições de norma, a produção de concreto deve produzir com média e limites de acordo com essas especificações. Nessas condições, o produtor estará fornecendo concreto conforme o especificado no projeto estrutural.

A limitação descrita acima não é imposta por Norma. O que se estabelece em Norma (ABNT, 1996) é que não se aceite concreto que apresente resistência inferior à resistência de projeto. Todavia, todo fabricante de concreto deve ser capaz de produzir dentro das especificações mencionadas, na medida em que o cálculo da resistência de dosagem pressupõe que existam limites mínimos e máximos. Ressaltase que um processo que não atenda a essas limitações impõe perdas aos consumidores. Essas perdas são comentadas adiante no texto.

O estudo da capacidade dos limites de produção refere-se à avaliação da capacidade do produtor de fabricar concreto que, aos 28 dias, apresente valores de resistência à compressão axial que atenda às especificações acima. Para o caso em estudo, as especificações do processo são as seguintes:

$$
L E I=18 \mathrm{MPa} ; A l v o=f_{c 28}=18+1,65 . S_{d}(\mathrm{MPa}) ; L E S=f_{c 28}+1,65 . S_{d}(\mathrm{MPa})
$$

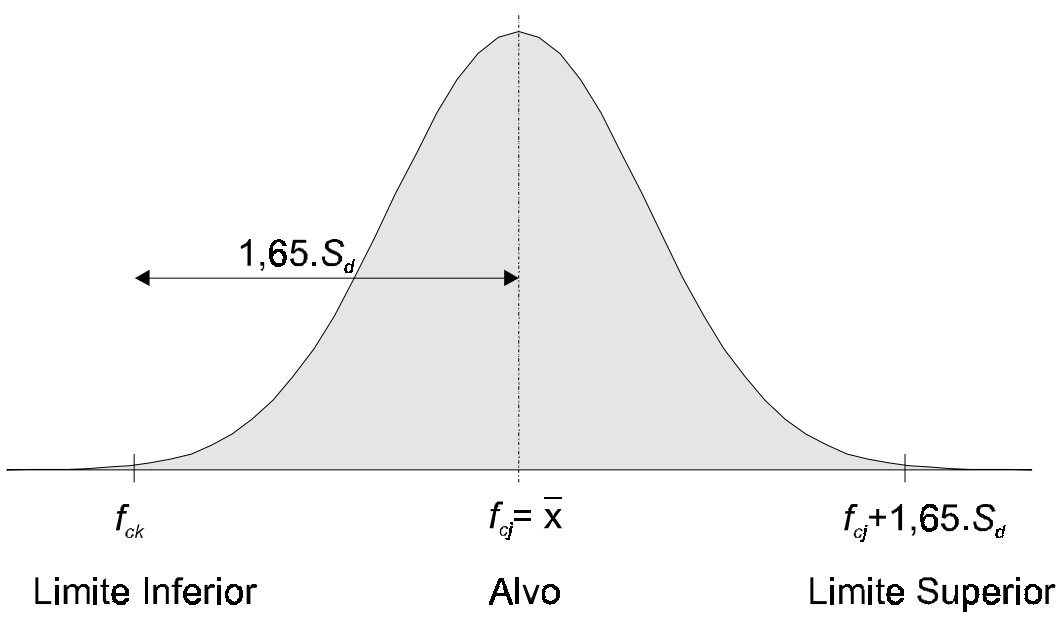

Figura 6 - Produção de concreto com alvo centrado na resistência de dosagem 
De acordo com a Norma (ABNT, 1996), quando o concreto for produzido com os mesmos materiais, mesmos equipamentos e sob condições similares de produção, o valor numérico de $S_{d}$ deve ser calculado com base em, no mínimo, 20 resultados consecutivos obtidos no intervalo de 30 dias, em período anterior ao fornecimento. Em nenhuma circunstância o valor de $S_{d}$ pode ser inferior a $2 \mathrm{MPa}$.

Segundo essas indicações, o desvio-padrão da produção de concreto deve ser estipulado antes do seu fornecimento. Essa condição, na prática, somente pode ser aplicada pelos produtores do concreto, pois apenas eles têm o conhecimento de qual o desviopadrão que sua produção apresenta antes de fornecer o material. Todavia, para o caso em análise, a elevada quantidade de valores de resistência à compressão do concreto aos 28 dias que se dispõe (374 amostras), torna a amostra suficientemente representativa da produção, considerando-se que cerca de $80 \%$ da produção de concreto destinava-se ao fornecimento da empresa construtora analisada. Como o concreto foi produzido sob condições similares, por tratar-se de um único produtor, é possível utilizar o desvio-padrão da amostra de 374 valores como estimador do desviopadrão do processo de produção $\left(S_{d}\right)$; o valor resultante é $S_{d}=3,6301(\mathrm{MPa})$. Substituindo o valor obtido na equação (11), tem-se:
Observa-se, pela análise dos resultados no quadro da Figura 7, que o processo não é capaz de produzir de acordo com as especificações. O índice $C_{p k}$ informa que o processo efetivamente não é capaz $\left(C_{p k}<1\right)$; o processo produz somente $90,75 \%$ de itens dentro das especificações. O índice $C_{p k}$ também informa que o processo está descentralizado $\left(C_{p k}<\right.$ $\left.C_{p}\right)$; no caso, a média do processo $(26,3662 \mathrm{MPa})$ é superior ao alvo das especificações (23,9897 MPa). Nota-se, também, que o processo apresenta dispersão superior ao permitido pelas especificações $\left(C_{p}<\right.$ $1)$. Dessa forma, mesmo centrado no alvo, o processo efetivamente não seria capaz.

A não-capacidade do processo de atender às especificações (limites de produção) implica na imposição de perdas ao consumidor. Para o processo em análise, segundo a classificação proposta por Shingo (1996) e Ohno (1997), a principal perda ocorrida é do tipo perdas por superprodução quantitativa, isto é, perdas devidas à produção de concreto com resistência acima do limite de especificação superior do processo. Essa perda está associada ao consumo de cimento maior que o necessário para que o concreto atenda à especificação de projeto.

Por definição, toda a produção acima da especificação de projeto $\left(f_{c k}\right)$ deveria ser considerada como perda por

$$
\text { Alvo }=f_{c 28}=18+1,65(3,63)=23,98 \mathrm{MPa} \text { e LES }=23,98+1,65(3,63)=29,97 \mathrm{Mpa} \text {. }
$$

Tendo-se estabelecido os limites de especificação (limites de produção, no caso), passa-se à avaliação da capacidade do processo em atender essas especificações, apresentada no quadro da Figura 7. superprodução quantitativa. Contudo, como a produção de concreto segue uma distribuição Normal e o processo está ajustado para produzir com alvo $f_{c j}$ superior ao $f_{c k}$, é da própria natureza do processo que

\section{CAPACIDADE DO PROCESSO}

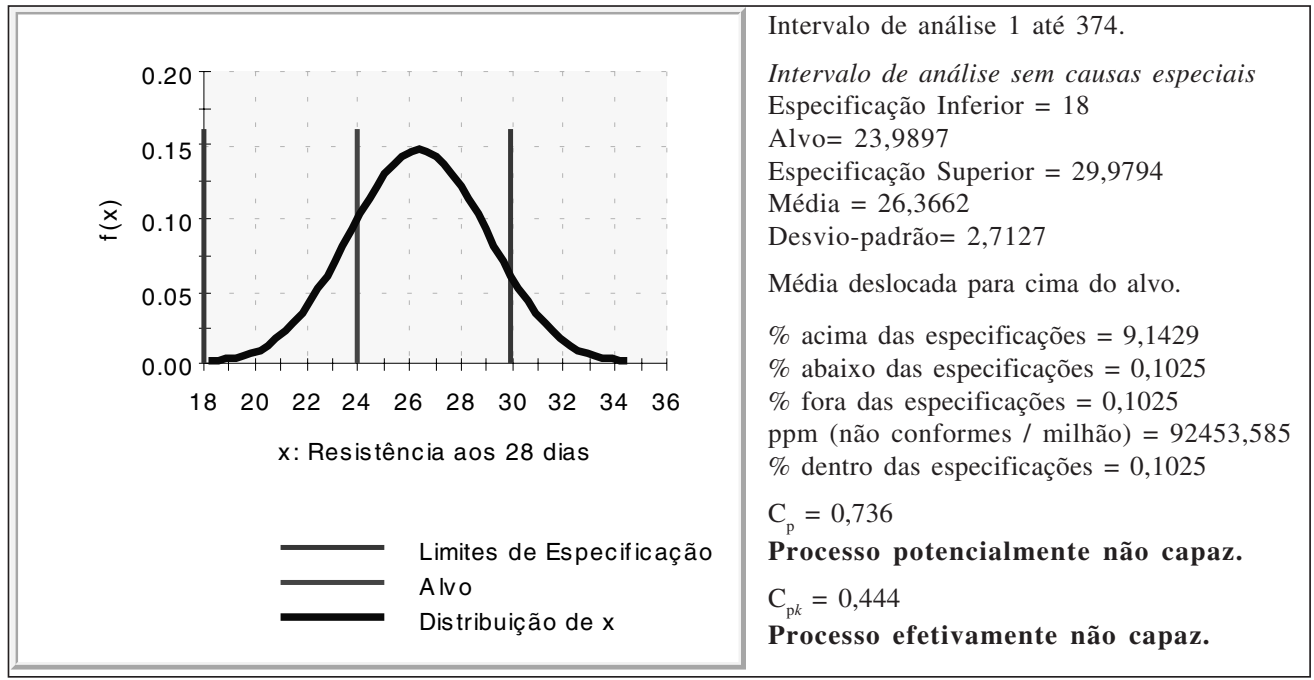

Figura 7 - Quadro com avaliação da capacidade dos limites de produção, após remoção de causas especiais 
se obtenha concreto com resistências acima do valor estipulado em projeto. Essa é uma restrição técnica que não pode ser evitada, apesar de poder ser melhorada, conforme proposta apresentada mais adiante. O que se propõe neste artigo é que existe um LES, inerente ao processo, estabelecido no cálculo da resistência de dosagem que, caso ultrapassado, impõe um ônus desnecessário aos consumidores do produto.

Mesmo sendo capaz de atender à especificação de projeto (apresentando capacidade técnica), o processo atual gera perdas aos consumidores. Na verdade, a resistência especificada em projeto é válida somente para critérios de aceitação do produto, ao passo que o custo real do concreto está relacionado com os materiais necessários para produzir uma certa resistência média $\left(f_{c j}\right)$. O custo de produção do concreto é função do custo dos seus materiais constituintes, notoriamente, o cimento. Esse material é responsável pela maior parcela de custo do produto (NEVILLE, 1997). Desta forma, para se produzir um concreto econômico, deve-se evitar, em sua dosagem, altos teores dessa matéria-prima. Como existe uma relação direta entre resistência e consumo de cimento, considerando-se uma trabalhabilidade pré-definida constante do concreto, constata-se que o fornecedor avaliado está onerando o consumidor por estar fabricando concreto com resistência acima das especificações, à medida que isso implica em maior consumo de cimento. Esse "excesso" de resistência é desnecessário para que a estrutura cumpra sua função e atenda às solicitações de carregamento impostas à mesma. Ou seja, o consumidor está pagando por um adicional de resistência que não lhe é útil e, ao contrário, pode ser prejudicial, como apresentado a seguir.

Pelo exposto, observa-se que apesar do processo atual de produção de concreto apresentar capacidade técnica $\left(f_{c k} \geq 18 \mathrm{MPa}\right)$, o mesmo não apresenta capacidade de limites de produção, o que acarreta em perdas para o consumidor. Portanto, o processo atual deve ser melhorado. Perdas por superprodução devem ser o principal foco de melhorias em um sistema produtivo, visto que auxiliam na geração de outros tipos de perdas. Para tanto, deve-se tornar o processo de produção do concreto capaz de produzir de acordo com os limites de produção propostos.

Duas ações podem ser tomadas para tornar o processo capaz: $i$ ) redução da média de produção e $i$ ) redução da variabilidade. Observa-se que reduzir a média do processo sem reduzir sua variabilidade pode acarretar na fabricação de produtos defeituosos, na medida em que o processo apresenta dispersão maior que as especificações $\left(C_{p}<1\right)$. Portanto, sugere-se inicialmente que a variabilidade do processo de produção seja reduzida, tornando-o potencialmente capaz $\left(C_{p} \geq 1\right)$. Em seguida, deve-se agir no sentido de centralizar o processo, que deve fabricar com alvo na resistência de dosagem, tornando o processo efetivamente capaz $\left(C_{p k}\right.$ $\geq 1$ ). Posteriormente, deve-se questionar as especificações atuais e, se possível, reduzí-las através de um processo contínuo de melhorias.

À medida em que a variabilidade de produção vai sendo reduzida (menores desvios-padrão), a média do processo pode ser gradativamente deslocada para a esquerda, aproximando-se do limite de especificação inferior do processo, que é o próprio valor da resistência de projeto $\left(f_{c k}\right)$. Assim, à medida em que o processo de produção mantém-se estável ao longo do tempo e apresenta menor variabilidade, pode-se reduzir o valor da resistência de dosagem (alvo) para a produção do concreto, sem acarretar perdas para produtor e consumidor. O produtor pode fabricar um concreto mais barato (menor consumo de matériasprimas), beneficiando o consumidor com redução de preços e aumento da confiabilidade no material fornecido, ao passo que se beneficia com possível aumento de mercado consumidor, já que oferece um produto mais barato com maior qualidade intrínseca.

\section{iii. Função de Perda Quadrática de Taguchi}

De acordo com a definição de $f_{c k}$, é permitida uma proporção de $5 \%$ de concreto abaixo do valor característico. Essa condição é levada em consideração no cálculo da resistência de dosagem. A constante 1,65 , na equação (9) foi estabelecida de forma que, na fabricação de um certo volume de concreto, uma proporção de 5\% possa estar abaixo da resistência característica. Essa quantidade não indica que o produtor está fabricando concreto de má qualidade ou esteja fornecendo intencionalmente concreto abaixo da especificação, visto que, por definição, permite-se que se fabrique nessas condições. Contudo, essa é uma visão do produtor.

Do ponto de vista do consumidor, de acordo com considerações de Norma, não se deve aceitar concreto que esteja abaixo do $f_{c k}$. Conseqüentemente, o produtor deve ser capaz de oferecer um produto que atenda a essa condição. Para o cliente não interessa concreto com valores abaixo do $f_{c k}$. Para atender a essa exigência, o produtor pode interferir em seu processo de fabricação de duas formas: $i$ ) elevando a média de produção e ii) reduzindo a dispersão dos dados. A média de fabricação foi previamente estabelecida pela resistência de dosagem, de acordo com a Norma; portanto, em tese, não pode ser elevada. Dessa forma, a opção mais plausível é a redução do desvio-padrão do processo.

Reduzir o desvio-padrão do processo significa conhecer profundamente o processo de produção e 
todas as variáveis que influenciam nos resultados obtidos. Desta forma, a maneira mais fácil e difundida entre os produtores para atender à exigência dos clientes por um concreto com resistência maior ou igual ao $f_{c k}$ é o aumento da média do processo de produção além de $f_{c j^{\circ}}$ Contudo, ao elevar-se a média da produção, o processo passa a não ser capaz de atender aos limites de produção, conforme verificado anteriormente. Sendo assim, os clientes passam a arcar com os custos adicionais de produção devido à ineficiência do produtor.

Para quantificar a perda monetária dos consumidores utiliza-se a função de perda de Taguchi, apresentada na equação (6). A utilização daquela função pressupõe o conhecimento da perda financeira associada a uma unidade de desvio do alvo (A). Para o caso do concreto, deve-se conhecer o custo adicional da produção do material com uma unidade de MPa acima ou abaixo do valor alvo. Estimou-se este valor como sendo igual a $\mathrm{A}=7,875$ (o preço médio de mercado para um concreto de $18 \mathrm{MPa}$ é de $\mathrm{R} \$ 141,75 / \mathrm{m}^{3}$ ). A média observada para a resistência à compreensão, conforme observado nas cartas de controle, é de 26,36 MPa e o valor estabelecido como alvo para esta característica é 23,98 . Substituindo essas informações na equação (6), obtém um valor de perda de $P=\mathrm{R} \$ 44,61 / \mathrm{m}^{3}$ de concreto produzido. No caso em estudo, a edificação incluía uma torre principal cuja estrutura utilizou um volume de concreto da ordem de $1.300 \mathrm{~m}^{3}$. Com as características apresentadas pelo material, o excesso de desempenho do concreto implicou numa perda monetária de $\mathrm{R} \$ 57.454,00$. Este custo adicional foi repassado ao consumidor, encarecendo o custo total da obra.

\section{Conclusões}

A aplicação do CEP, neste trabalho, teve como principal foco monitorar o fornecimento de concreto a obras de edificações residenciais. A idéia foi dispor de uma ferramenta que oferecesse ao consumidor a habilidade de avaliar a capacidade do fornecedor do referido insumo de atender às suas necessidades.

Através do estudo realizado, pôde-se averiguar que, apesar do fornecedor estar oferecendo um concreto de acordo com a especificação de projeto, era imposto ao consumidor um ônus financeiro desnecessário. Verificou-se que o consumidor está pagando por um excesso de resistência que não lhe é útil podendo, ao contrário, ser-lhe prejudicial. O que se pode concluir é que o parâmetro atual para aceitação do concreto endurecido $\left(f_{c k}\right)$, apesar de ser adequado do ponto de vista técnico, do ponto de vista financeiro e de qualidade, não é suficiente. Ao não levar em consideração um limite máximo para a aceitação do concreto, conforme proposto neste trabalho, o consumidor está arcando com um custo devido à ineficiência do produtor de controlar seu processo de produção. Uma avaliação adequada do fornecimento do concreto deve levar em consideração não só um limite mínimo descrito pelo $f_{c k}$, mas também um limite máximo de especificação. Tais limites, mínimo e máximo, foram denominados neste trabalho por limites de produção.

Outro ponto importante a ser ressaltado é que, levando em consideração a existência dos limites de produção, o produtor pode constantemente avaliar seu processo de produção de acordo com esses parâmetros, reduzindo-os ao longo do tempo. Isso significa oferecer um produto com menor variabilidade e com valores mais próximos da especificação de projeto. Para o consumidor, significa receber um concreto que atenda as suas necessidades a um menor preço. Para o produtor, significa aumento de mercado consumidor pela oferta de um produto mais confiável e com maior qualidade intrínseca. No limite, pode-se cada vez menos depender de operações de ensaio de concreto (salvo o que é determinado por Norma) para aferir a qualidade do material consumido, o que também significa redução de custos de produção. Propõe-se, então, a adoção dos limites de produção discutidos neste artigo como parâmetros correntes para a aceitação do concreto utilizado em obra e avaliação de sua qualidade.

Finalmente, verifica-se que o CEP é uma ferramenta útil para o registro e o acompanhamento da qualidade do concreto e do desempenho de seus fornecedores ao longo do tempo. O CEP é uma ferramenta capaz de fornecer uma descrição detalhada do comportamento de um processo, identificando sua variabilidade e possibilitando seu controle ao longo do tempo, através da coleta continuada de dados e da análise e bloqueio de possíveis causas especiais, responsáveis pela instabilidade do processo em estudo. Destaca-se que, nas empresas de construção civil, de forma geral, apesar de existirem informações sobre a resistência à compressão do concreto, obtidas através dos ensaios tecnológicos, as mesmas não são organizadas adequadamente para manter um registro da qualidade dos fornecedores e do próprio desempenho do concreto utilizado, no tempo. Sob esse aspecto, o CEP é uma ferramenta simples e eficiente que possibilita o registro das informações e permite e análise do desempenho de determinados parâmetros ao longo do tempo, sendo, então, uma ferramenta útil para as empresas do setor. Desta forma, propõe-se a aplicação do CEP como uma ferramenta que pode ser amplamente utilizada na construção civil como meio de alcançar melhorias contínuas na construção de edificações, contribuindo para o desenvolvimento do setor. 


\section{Referências}

ASSOCIAÇÃO BRASILEIRA DE NORMAS TÉCNI-

CAS. Concreto: Preparo, Controle e Recebimento:

NBR 12655. Rio de Janeiro, 1996.

\section{ASSOCIAÇÃO BRASILEIRA DE NORMAS TÉCNI-}

CAS. Projeto e Execução de Obras de Concreto

Armado: NBR 6118. Rio de Janeiro, 1978.

BOTHE, D. R. Measuring Process Capability:

techniques and calculations for quality and

manufacturing engineers. New York: McGraw-Hill, 1997.

DUNCAN, A. J. Quality Control and Industrial

Statistics. 5.ed. Chicago: Irwin, 1986.

HELENE, P. R. L. Controle de Qualidade do Concreto. São Paulo, 1980. 129p. Dissertação de Mestrado em Engenharia Civil, Escola Politécnica, Universidade de São Paulo.

HELENE, P. R. L.; TERZIAN, P. Manual de Dosagem e Controle do Concreto. São Paulo: PINI; SENAI, 1992.

JURAN, J. M.; GRYNA, F. M. Quality Planning and Analysis: from product development through use. 3.ed. New York: McGraw-Hill, 1993.
KOTZ, S.; LOVELACE, C. R. Process Capability Indices in Theory and Practice. New York: Arnold, 1998.

MONTGOMERY, D. C. Introduction to Statistical Quality Control, 3.ed. New York: John Wiley, 1996.

NEVILLE, A. M. Propriedades do Concreto, 2.ed. São Paulo : PINI, 1997.

OHNO, T. O Sistema Toyota de Produção: além da produção em larga escala. Porto Alegre: Bookman, 1997.

PROCEP 99, versão 3.01. Manual do Usuário. Porto Alegre: Maxxi Gestão Empresarial, 1999. 4 disquetes.

RIBEIRO, J. L. D.; CATEN, C. Controle Estatístico de Processos. Porto Alegre, 2000. Apostila de Curso. Programa de Pós-Graduação em Engenharia de Produção, Escola de Engenharia, Universidade Federal do Rio Grande do Sul.

SHINGO, S. O Sistema Toyota de Produção do ponto de vista da engenharia de produção. Porto Alegre: Bookman, 1996.

TAGUCHI, G.; ELSAYED, E.A.; HSIANG, T. Engenharia da Qualidade em Sistemas de Produção. São Paulo: McGraw-Hill, 1990.

Submetido em janeiro/2002

Aprovado em outubro/2004 